\title{
The prognostic influence of body mass index, resting energy expenditure and fasting blood glucose on postoperative patients with esophageal cancer
}

\author{
Ning $\mathrm{Wu}^{1+}$, Yongjun Zhu ${ }^{1 \dagger}$, Dhruba Kadel ${ }^{2}$, Liewen Pang ${ }^{1}$, Gang Chen ${ }^{1}$ and Zhiming Chen ${ }^{1 *}$
}

\begin{abstract}
Background: Body mass index (BMI), resting energy expenditure (REE) and fasting blood glucose (FBG) are major preoperative assessments of patients' nutrition and metabolic state. The relations and effects of these indices on esophageal cancer patients' postoperative short-term and long-term outcomes remain controversial and unclear. We aimed to study the impact of BMI, REE and FBG in esophageal cancer patients undergoing esophagectomy.

Methods: Three hundred and six esophageal cancer patients who underwent esophagectomy were observed retrospectively. Clinical characteristics, postoperative complications and survival analysis were compared among different BMI, REE and FBG groups.

Results: There were significant linear relationships between REE, BMI and FBG indices, patients with low BMI tended to have low REE $(p<0.001)$ and low FBG $(p=0.003)$. No significant difference was found in case of mortality and postoperative complications among different groups. Low BMI $\left(X^{2}=6.141, p=0.046\right)$, REE $\left(X^{2}=6.630, p=0.010\right)$ and FBG $\left(X^{2}=5.379, p=0.020\right)$ were related to poor survival. FBG $\leq 90 \mathrm{mg} / \mathrm{dL}$ was independently associated with poor survival ( $\mathrm{HR}=0.695 ; 95 \% \mathrm{Cl} 0.489-0.987, p=0.042)$. BMI and REE came to be stronger prognostic factors on lymph node-negative patients and proved to be independent prognostic indicators ( $\mathrm{HR}=0.540 ; 95 \% \mathrm{Cl} 0.304-0$. 959, $p=0.035$ and $\mathrm{HR}=0.457 ; 95 \% \mathrm{Cl} 0.216-0.967, p=0.041$, respectively).
\end{abstract}

Conclusions: BMI, REE and FBG are important prognostic factors in patients with esophageal cancer undergoing esophagectomy and preoperative evaluation of these indices help to determine the prognosis in these patients.

Keywords: Esophageal cancer, Body mass index, Resting energy expenditure, Fasting blood glucose, Prognosis

\section{Background}

Esophageal cancer (EC) is the eighth most common cancer and the sixth leading cause of cancer mortality worldwide [1]. Esophageal adencarcinoma (EAC) and esophageal squamous cell carcinoma (ESCC) are the most frequent histological subtypes. ESCC is the dominant histological subtype in china [2]. The potential prognostic indicators of esophageal cancer include histological variants (histological grading, differentiation, invasion

* Correspondence: czm_md@163.com

${ }^{\dagger}$ Equal contributors

${ }^{1}$ Department of Cardio-thoracic Surgery, HuaShan Hospital of Fudan

University, Shanghai 200040, People's Republic of China

Full list of author information is available at the end of the article depth and classification of lymph node metastasis) and nutrition or inflammation based prognostic factors (total lymphocyte counts, neutrophil to lymphocyte ratio (NLR), serum albumin and so on). BMI, REE and FBG, which are widely used to assess preoperative nutritional and metabolic status, have also been described to be prognostic predictors in several tumors [3].

Previous studies reported that high BMI was associated with increased risk of EAC while low BMI with ESCC [4]. High BMI in surgical patients is thought to be associated with increased comorbidities and postoperative complications, but the influence of high BMI on survival in patients undergoing esophagectomy is controversial. Hayashi found patients with high BMI showed 
better overall survival (OS) and disease-free survival (DFS) because of the early clinical diagnosis [5]. In contrast to this, Yoon pointed out that high BMI was independently associated with two-fold worsening of DFS, and OS after surgery for EAC [6]. Blom concluded that BMI had no prognostic value on short-term and longterm outcomes [7]. Compared with the previous studies, the mean BMI in Western populations was higher and had a greater incidence rate of EAC whereas the mean BMI in Chinese population was found to be lower with predominant ESCC. The effect of low BMI on postoperative complications and long-term survival remains unclear. So our study assessed the relationship between BMI and postoperative complications and long-term survival in Chinese population.

Disorder of energy metabolism is a common phenomenon in cancer patients. The energy metabolic status among different cancers may not be the same. Many researchers assessed the resting energy expenditure on cancer patients and no unanimous conclusions have been drawn. In this study, patients' preoperative REE was an estimated variable, and calculated by the Mifflin-St. Jeor equation [8]. REE is the sum of the metabolic activities of internal body and can reflect patient's physiques and muscle volumes, and REE per $\mathrm{kg}$ total body weight (REE/ $\mathrm{kg}$ ) may reflect the diffusion and metabolic rate of muscle more accurately. So both REE and REE/kg were used to explore its effects on short-term and long-term outcomes on esophageal cancer patients.

Epidemiologic evidence suggests that elevated blood glucose is associated with many forms of cancer [9]. However, opinions toward the association between elevated blood glucose and outcomes are mixed. Elevated blood glucose may promote cancer progression and lead to poor outcomes via pathways mediated high levels of insulin and insulin-like growth factor [10]. On the other hand, some studies proposed that diabetes-related microvessel changes might play a protective role against "neoplastic" cell metastasis in cancer patients and enhance cancer prognosis [11]. For EC, the relationship between the circulating glucose levels and prognosis has never been reported. To examine effects of fasting glucose levels at time of cancer diagnosis on postoperative outcomes is another aim of this study.

So the purpose of the study is to investigate the prognostic value using combined assessment of BMI, REE and FBG in esophageal cancer patients.

\section{Methods}

\section{Patients}

Patients who underwent esophagectomy and lymph node dissections during Sep 1, 2003 to Dec 31, 2008 were observed. Twenty-three patients who had palliative or R1/R2 resections were excluded. Patients who had histology other than SCC or AC (one lymphoma, one melanoma, one neuroendocrine carcinoma, one stromal tumor and two small cell carcinoma) were excluded. Patients who received neoadjuvant therapy were also excluded. Three hundred and six patients with histologic documentation of AC or SCC were included. All patients provided written consent and this retrospective study was approved by the Institutional Review Board of Huashan Hospital, Fudan University.

\section{Clinical data}

Preoperative staging was performed in all patients by means of barium meal test, fibro-gastroscopy, computed tomography of the chest and abdomen and ultrasound of the neck and retroperitoneal lymph nodes. Some patients also received whole body positron emission tomography (PET)-CT scanning. All patients were assessed for physiological ability to undergo esophagectomy. These evaluations included pulmonary function test, cardiac function test and nutritional assessment.

One hundred and eighty-six patients with tumors in middle or lower thoracic esophagus and no evidence of lymph node involvement in the superior mediastinum or neck region received transthoracic esophagectomy via left thoracotomy which also included a two-field lymphadenectomy; 53 patients with tumors in the middle or upper thoracic esophagus and possible lymph node metastasis in the superior mediastinum or neck region received McKeown 3-hole esophagectomy with three-field lymphadenectomy; 67 patients with tumors in the esophagogastric junction received esophagogastrectomy through median laparotomy.

TNM staging was performed according to the AJCC 7 th edition guidelines. Patients were followed up every 6 months for the first 3 years and then annually. Survival time was measured as the time from the date of surgery to the date of death or the latest follow-up time. Endoscopy, CT, PET-CT and Radionuclide bone scan were performed if recurrent or metastatic disease was suspected.

Patients' weight and height were measured at their first hospitalization. BMI was calculated as weight in kilograms divided by height in meters squared.

REE was calculated by Mifflin-St. Jeor equation. The applied technique to calculate BMI is as follows: for males $=10 *$ weight $(\mathrm{kg})+6.25 *$ height $(\mathrm{cm})-5 *$ age $(\mathrm{y})+5$; for females $=10 *$ weight $(\mathrm{kg})+6.25 *$ height $(\mathrm{cm})-5 *$ age $(\mathrm{y})-161$. Both REE and REE/kg were calculated.

The serum FBG concentration of patients was measured in the morning during the first hospitalization by hexokinase method after fasting for $10 \mathrm{~h}$. Serum albumin was measured by means of the bromocresol purple 
method using automated equipments, and all patients were screened and excluded from acute and chronic liver disease. The complete blood count test (leukocyte, neutrophil, lymphocyte, monocyte, eosinophil, basophil, platelet counts, and hemoglobin) was carried out by an automated haematology analyser within one week prior to surgery. NLR was calculated as the ratio of neutrophils to lymphocytes in peripheral blood. These reagents and equipments were convenience-validated and standardized in our central clinical laboratory.

The 6-month preoperative weight loss was also measured and patients were divided into three categories: No/Little (loss of 0 to $5 \%$ body weight), Middle (loss of 5 to $10 \%$ body weight) and Large (loss more than $10 \%$ body weight).

During the first few days after surgery, patients were treated with total parenteral nutrition. An initial dose of 5-10 kcal.day ${ }^{-1} \mathrm{~kg}^{-1}$ of enteral nutrition was supplied via a duodenum or jejunum feeding tube from the 2nd or 3rd postoperative day and gradually increased to the full dose of $25-30 \mathrm{kcal} \cdot \mathrm{day}^{-1} \mathrm{~kg}^{-1}$. Some patients with low BMI or low serum albumin levels were treated with full dose of enteral nutrition from one week before surgery to the tenth day after surgery.

\section{Statistical analysis}

All statistical analysis was performed with SPSS 16.0. Spearman rank order correlation coefficient (Spearman's rho) for nonparametric data was used. Univariate analysis of survival was performed using Kaplan-Meier method and log-rank test to estimate the prognostic value. Multivariate analysis of survival was performed using Cox-regression model to estimate hazard ratios (HRs) with $95 \%$ confidence intervals (CI) and identify independent prognostic factors. The level of significance was set to $p<0.05$.

\section{Results}

\section{Patient characteristics}

The clinical characteristics and 5-years survival rate are summarized in Table 1 . The median follow-up time was 37 months. The overall 1-, 3- and 5-year survival rate was $86.6,60.8$ and $47.1 \%$ respectively.

The BMI distribution was as follows: low $\left(<20 \mathrm{~kg} / \mathrm{m}^{2}\right)$, $n=81$ (26.5 \%); normal $\left(20-25 \mathrm{~kg} / \mathrm{m}^{2}\right), n=186(60.8 \%)$ and high $\left(>25 \mathrm{~kg} / \mathrm{m}^{2}\right), n=39(12.7 \%)$. The median REE was $1387.5 \mathrm{kcal} \mathrm{day}^{-1}$ for male and $1064.0 \mathrm{kcal} \mathrm{day}^{-1}$ for female where we defined the median REE as the cutoff point and stratified patients into low REE group (male $<$ 1387.5 and female <1064.0), $n=154(50.3 \%)$ and high REE group (male $\geq 1387.5$ and female $\geq 1064.0$ ), $n=152$ (49.7\%). The median REE/kg was 21.49 kcal.day ${ }^{-1} \mathrm{~kg}^{-1}$. Compared with $245(80.1 \%)$ patients with $\mathrm{REE} / \mathrm{kg}<$ 23.2, 61 (19.9 \%) patients with REE/kg $\geq 23.2$ had significant worse survival, so $23.2 \mathrm{kcal} . \mathrm{day}^{-1} \mathrm{~kg}^{-1}$ was set as the cutoff point. We divided the patients into two groups according to serum FBG concentration where 108 patients $(35.3 \%)$ with low FBG $(\leq 90 \mathrm{mg} / \mathrm{dL})$ and 198 patients $(64.7 \%)$ with high FBG $(>90 \mathrm{mg} / \mathrm{dL})$.

\section{Patient characteristics by BMI, REE, REE/kg and FBG}

As shown in Table 2. Spearman's rho indicated that patients with age $>65$ years $(p<0.001)$ and advanced Tstage $(p=0.040)$ were more likely to fall in the low REE class. Smoking patients were more likely to be associated with low BMI class $(p=0.013)$, low FBG class $(p=0.039)$ but high REE $/ \mathrm{kg}$ class $(p=0.001)$.

It was interesting to explore the relationship between $\mathrm{REE}$ and REE $/ \mathrm{kg}$. Both high REE and low REE/kg patients were found to have better survival, which was consistent with the spearman correlation analysis that found patients with high REE tended to have lower REE/ $\mathrm{kg}(p<0.001)$.

There were significant linear relations between BMI, REE, and FBG, patients with low BMI tended to have low REE $(p<0.001)$ and low FBG $(p=0.003)$. The trend of a linear association between REE and FBG could also be seen $(p=0.011)$.

There were close relations between $\mathrm{REE} / \mathrm{kg}$ and weight lost or BMI, patients with high $\mathrm{REE} / \mathrm{kg}$ have been found to lose more weight $(p=0.006)$ and have lower BMI $(p<0.001)$.

Low FBG was more likely to be seen in patients with high REE/kg $(p=0.025)$ and low albumin $(p<0.001)$.

\section{Comorbidities, postoperative mortality and postoperative complications}

Preoperative comorbidities, mortality and postoperative complications among different groups of BMI, REE, $\mathrm{REE} / \mathrm{kg}$ and FBG were presented in Table 2. COPD appeared to be more frequent in low REE patients $(p=$ 0.022 ), and diabetes was more common in high BMI patients $(p=0.006)$. All the seven patients with cardiovascular disease belonged to low FBG class $(p<0.001)$. Observing the short-term outcomes, no significant difference was found in postoperative mortality and major postoperative complications among different BMI, REE, $\mathrm{REE} / \mathrm{kg}$ and FBG groups.

\section{Nutrition or inflammation-based prognostic factors}

Univariate analysis of nutrition or inflammation-based prognostic factors found to be serum albumin $(p<$ $0.001)$, but not Total lymphocyte counts $(p=0.780)$ or NLR ( $p=0.787)$, which was positively related to survival. The spearman correlation analysis found higher serum albumin levels were observed in high BMI, REE and FBG but in low REE/kg groups. 
Table 1 Patient characteristics and univariate analysis

\begin{tabular}{|c|c|c|c|c|}
\hline Factors & & $\mathrm{N}$ & $\begin{array}{l}\text { 5-year } \\
\text { survival (\%) }\end{array}$ & $p$ \\
\hline \multirow[t]{2}{*}{ Age, year } & $\leq 65$ & 210 & 53.3 & 0.003 \\
\hline & $>65$ & 96 & 34.6 & \\
\hline \multirow[t]{2}{*}{ Sex } & Male & 235 & 44.0 & 0.039 \\
\hline & Female & 71 & 57.8 & \\
\hline \multirow[t]{2}{*}{ Histology } & $A C$ & 98 & 49.7 & 0.590 \\
\hline & SCC & 208 & 45.7 & \\
\hline \multirow[t]{3}{*}{ Surgical type } & Transthoracic & 186 & 47.0 & 0.701 \\
\hline & McKeown & 53 & 40.4 & \\
\hline & Transabdominal & 67 & 51.2 & \\
\hline \multirow[t]{3}{*}{ Differentiation } & Well & 38 & 61.9 & 0.000 \\
\hline & Moderately & 173 & 55.1 & \\
\hline & Poorly & 95 & 24.9 & \\
\hline \multirow[t]{4}{*}{ T stage } & $\mathrm{Tis} / \mathrm{T} 1$ & 31 & 82.2 & 0.000 \\
\hline & $\mathrm{T} 2$ & 65 & 62.1 & \\
\hline & T3 & 159 & 43.3 & \\
\hline & T4a & 51 & 17.1 & \\
\hline \multirow[t]{4}{*}{ N stage } & NO & 156 & 67.5 & 0.000 \\
\hline & $\mathrm{N} 1$ & 73 & 38.6 & \\
\hline & N2 & 52 & 14.2 & \\
\hline & N3-4 & 25 & 9.5 & \\
\hline \multirow[t]{3}{*}{ TNM stage } & $0-1$ & 42 & 80.5 & 0.000 \\
\hline & $\|$ & 118 & 66.5 & \\
\hline & III & 146 & 21.3 & \\
\hline \multirow[t]{3}{*}{ Weight lost } & No/Little & 203 & 46.5 & 0.555 \\
\hline & Middle & 50 & 56.8 & \\
\hline & Large & 53 & 41.7 & \\
\hline \multirow{2}{*}{$\begin{array}{l}\text { Adjuvant } \\
\text { Chemoradiation }\end{array}$} & Yes & 78 & 41.7 & 0.187 \\
\hline & No & 228 & 48.8 & \\
\hline \multirow[t]{3}{*}{ Albumin } & $<35 \mathrm{~g} / \mathrm{l}$ & 36 & 26.7 & 0.000 \\
\hline & $35-40 \mathrm{~g} / \mathrm{l}$ & 132 & 41.6 & \\
\hline & $>40 \mathrm{~g} / \mathrm{l}$ & 138 & 57.8 & \\
\hline \multirow[t]{3}{*}{ Lymphocyte } & $<1.1^{*} 10^{9}$ & 42 & 48.7 & 0.780 \\
\hline & $1.1-3.2^{*} 10^{9}$ & 228 & 47.5 & \\
\hline & $>3.2^{*} 10^{9}$ & 36 & 42.6 & \\
\hline \multirow[t]{2}{*}{ NLR } & $<5$ & 289 & 47.1 & 0.787 \\
\hline & $\geq 5$ & 17 & 47.1 & \\
\hline \multirow[t]{2}{*}{ REE/kg } & $<23.2$ & 245 & 50.4 & 0.024 \\
\hline & $\geq 23.2$ & 61 & 35.2 & \\
\hline \multirow[t]{2}{*}{ REE } & Low & 154 & 40.4 & 0.010 \\
\hline & High & 152 & 55.3 & \\
\hline \multirow[t]{2}{*}{ FBG } & Low & 108 & 35.0 & 0.020 \\
\hline & High & 198 & 51.7 & \\
\hline
\end{tabular}

Table 1 Patient characteristics and univariate analysis (Continued)

\begin{tabular}{lllll}
\hline BMI & Low & 81 & 36.8 & $\mathbf{0 . 0 4 6}$ \\
& Normal & 186 & 49.1 & \\
High & 39 & 62.8 & \\
\hline Cl confidence interval, OR odds ratio & & \\
The results were in bold, if the $95 \% \mathrm{Cl}$ excluded 1 or $p<0.05$
\end{tabular}

\section{Univariate, multivariate and subgroup analysis}

To evaluate the prognostic factors potentially related to survival, univariate analysis was applied (Table 1) and found no statistical associations of histologic subtype, surgical type, weight loss and adjuvant chemoradiation with OS. The prognostic factors were age, sex, differentiation, T-stage, $\mathrm{N}$-stage, BMI $\left(X^{2}=6.141, p=0.046\right.$, Fig. 1$)$, albumin $\left(X^{2}=19.761, p<0.001\right.$, Fig. 2$)$, REE $\left(X^{2}=6.630\right.$, $p=0.010), \mathrm{REE} / \mathrm{kg}\left(X^{2}=5.063, p=0.024\right.$, Fig. 3$)$ and FBG $\left(X^{2}=5.379, p=0.020\right.$, Fig. 4). Patients with low BMI, REE, FBG and high REE/kg had significant worse survival.

Variables significant (age, sex, differentiation, T-stage, $\mathrm{N}$-stage, albumin, BMI, REE, REE/kg and FBG) in Univariate analysis were included in a multivariate analysis (Table 3), which did not show a significant association between BMI ( $\mathrm{HR}=0.945$; $95 \%$ CI $0.660-1.351, p=$ 0.755), REE (HR $=1.101 ; 95 \%$ CI 0.718-1.688, $p=0.660)$ or REE $/ \mathrm{kg}(\mathrm{HR}=1.164 ; 95 \%$ CI $0.717-1.890, p=0.540)$ and OS. Age, differentiation, T-stage, $\mathrm{N}$-stage, albumin $(\mathrm{HR}=0.757 ; 95 \% \mathrm{CI} 0.589-0.973, p=0.030)$ and FBG $(\mathrm{HR}=0.695$; $95 \% \mathrm{CI} 0.489-0.987, p=0.042)$ were independent prognostic factors.

In order to assess the impact of BMI and REE on different tumor stages, we divided patients into subgroups on the basis of N-stage (N0 vs. N1-4). Patients with higher BMI and REE had significantly better OS in subgroup of N0 $\left(X^{2}=15.507 p<0.001\right.$ and $X^{2}=14.717$, $p<0.001$, respectively), but no statistical significance in subgroup of N1-4 $\left(X^{2}=1.952, P=0.377\right.$ and $X^{2}=0.386$, $p=0.534$, respectively). Multivariate analysis of subgroups revealed BMI $(\mathrm{HR}=0.540 ; 95 \%$ CI 0.304-0.959, $p=0.035)$ and $\operatorname{REE}(\mathrm{HR}=0.457 ; 95 \%$ CI $0.216-0.967$, $p=0.041)$ were independent prognostic factors for N0 patients but not for N1-4 patients.

\section{Discussion}

Our study identified that FBG level $\leq 90 \mathrm{mg} / \mathrm{dL}$ was independently associated with poor survival and also confirmed that advanced cancer stages remain the most powerful prognostic factors. In addition, we observed that BMI, REE and FBG were significant prognostic factors, but the prognostic value of BMI and REE is not the same between different lymph node metastasis statuses. For metastatic esophageal cancers, the most important prognostic factors were FBG, albumin and cancer staging including differentiation and invasion depth 
Table 2 Associations among characteristics, BMI, REE, REE/kg and FBG

\begin{tabular}{|c|c|c|c|c|c|c|c|c|c|c|c|c|c|}
\hline \multirow[t]{3}{*}{ Factors } & \multicolumn{4}{|c|}{ BMI, $\mathrm{kg} / \mathrm{m}^{2}$} & \multicolumn{3}{|c|}{ REE, kcal day ${ }^{-1}$} & \multicolumn{3}{|c|}{ REE $/ \mathrm{kg}$, kcal day ${ }^{-1}$} & \multicolumn{3}{|c|}{$\mathrm{FBG}, \mathrm{mg} / \mathrm{dL}$} \\
\hline & $<20$ & $20-25$ & $>25$ & $p$ & Low & High & $p$ & Low & High & $p$ & $\leq 90$ & $>90$ & $p$ \\
\hline & 81 & 186 & 39 & & 154 & 152 & & 245 & 61 & & 108 & 198 & \\
\hline \multicolumn{14}{|l|}{ Age } \\
\hline$\leq 65$ & 50 & 134 & 26 & 0.332 & 87 & 123 & 0.000 & 157 & 53 & 0.001 & 73 & 137 & 0.774 \\
\hline$>65$ & 31 & 52 & 13 & & 67 & 29 & & 88 & 8 & & 35 & 61 & \\
\hline \multicolumn{14}{|l|}{ Sex } \\
\hline Male & 65 & 141 & 29 & 0.408 & 118 & 117 & 0.942 & 174 & 61 & 0.000 & 88 & 147 & 0.153 \\
\hline Female & 16 & 45 & 10 & & 36 & 35 & & 71 & 0 & & 20 & 51 & \\
\hline \multicolumn{14}{|l|}{ Histology } \\
\hline SCC & 54 & 132 & 22 & 0.561 & 103 & 105 & 0.682 & 165 & 43 & 0.639 & 81 & 127 & 0.052 \\
\hline$A C$ & 27 & 54 & 17 & & 51 & 47 & & 80 & 18 & & 27 & 71 & \\
\hline \multicolumn{14}{|l|}{ Differentiation } \\
\hline Well & 7 & 28 & 3 & 0.869 & 19 & 19 & 0.507 & 31 & 7 & 0.552 & 14 & 24 & 0.557 \\
\hline Moderately & 50 & 98 & 25 & & 91 & 82 & & 140 & 33 & & 63 & 110 & \\
\hline Poorly & 24 & 60 & 11 & & 44 & 51 & & 74 & 21 & & 31 & 64 & \\
\hline \multicolumn{14}{|l|}{ T stage } \\
\hline $\mathrm{Tis} / \mathrm{T1}$ & 8 & 19 & 4 & 0.172 & 12 & 19 & 0.040 & 27 & 4 & 0.124 & 12 & 19 & 0.499 \\
\hline $\mathrm{T} 2$ & 14 & 42 & 9 & & 30 & 35 & & 54 & 11 & & 22 & 43 & \\
\hline T3 & 42 & 93 & 24 & & 81 & 78 & & 126 & 33 & & 50 & 109 & \\
\hline $\mathrm{T} 4 \mathrm{a}$ & 17 & 32 & 2 & & 31 & 20 & & 38 & 13 & & 24 & 27 & \\
\hline \multicolumn{14}{|l|}{ N stage } \\
\hline No & 36 & 98 & 22 & 0.241 & 73 & 83 & 0.476 & 131 & 25 & 0.262 & 54 & 102 & 0.551 \\
\hline N1 & 20 & 44 & 9 & & 42 & 31 & & 55 & 18 & & 28 & 45 & \\
\hline $\mathrm{N} 2$ & 20 & 27 & 5 & & 26 & 26 & & 38 & 14 & & 22 & 30 & \\
\hline N3-4 & 5 & 17 & 3 & & 13 & 12 & & 21 & 4 & & 4 & 21 & \\
\hline \multicolumn{14}{|l|}{ Bad habits } \\
\hline Smoking & 51 & 86 & 17 & & 77 & 77 & 0.909 & 112 & 42 & 0.001 & 63 & 91 & 0.039 \\
\hline Drinking & 26 & 60 & 11 & & 46 & 51 & 0.490 & 74 & 23 & 0.261 & 38 & 59 & 0.355 \\
\hline \multicolumn{14}{|l|}{ Comorbidities } \\
\hline Highblood & 12 & 35 & 12 & 0.063 & 27 & 32 & 0.437 & 50 & 9 & 0.318 & 16 & 43 & 0.145 \\
\hline Copd & 12 & 18 & 5 & 0.478 & 24 & 11 & 0.022 & 29 & 6 & 0.662 & 13 & 22 & 0.809 \\
\hline Cardiovascular disease & 2 & 5 & 0 & 0.551 & 6 & 1 & 0.058 & 5 & 2 & 0.564 & 7 & 0 & 0.000 \\
\hline Arrhythmia & 7 & 16 & 8 & 0.129 & 14 & 17 & 0.546 & 27 & 4 & 0.303 & 14 & 17 & 0.227 \\
\hline Diabetes & 15 & 41 & 18 & 0.006 & 35 & 39 & 0.551 & 66 & 8 & 0.024 & 0 & 74 & 0.000 \\
\hline Mortality & 1 & 5 & 1 & 0.970 & 6 & 1 & 0.058 & 6 & 1 & 0.706 & 3 & 4 & 0.673 \\
\hline \multicolumn{14}{|l|}{ Postoperative complications } \\
\hline Fistula & 6 & 6 & 3 & 0.083 & 12 & 3 & 0.182 & 9 & 6 & 0.259 & 6 & 9 & 0.825 \\
\hline Sepsis & 9 & 6 & 6 & 0.208 & 15 & 6 & 0.260 & 12 & 9 & 0.125 & 9 & 12 & 0.673 \\
\hline Pneumonia & 7 & 11 & 8 & 0.615 & 16 & 10 & 0.892 & 20 & 6 & 0.676 & 8 & 18 & 0.233 \\
\hline Respiratory insufficiency & 6 & 9 & 6 & 0.846 & 14 & 7 & 0.692 & 18 & 3 & 0.504 & 7 & 14 & 0.122 \\
\hline Arrhythmia & 14 & 33 & 8 & 0.661 & 30 & 25 & 0.419 & 45 & 10 & 0.720 & 18 & 37 & 0.491 \\
\hline Cardiac insufficiency & 8 & 38 & 4 & 0.068 & 30 & 20 & 0.950 & 42 & 8 & 0.125 & 12 & 38 & 0.136 \\
\hline \multicolumn{14}{|l|}{ Albumin } \\
\hline$<35 \mathrm{~g} / \mathrm{l}$ & 16 & 19 & 1 & 0.001 & 29 & 7 & 0.000 & 26 & 10 & 0.009 & 20 & 16 & 0.000 \\
\hline
\end{tabular}


Table 2 Associations among characteristics, BMI, REE, REE/kg and FBG (Continued)

\begin{tabular}{|c|c|c|c|c|c|c|c|c|c|c|c|c|c|}
\hline $35-40 \mathrm{~g} /$ & 38 & 78 & 16 & & 68 & 64 & & 99 & 33 & & 55 & 77 & \\
\hline$>40 \mathrm{~g} / \mathrm{l}$ & 27 & 89 & 22 & & 57 & 81 & & 120 & 18 & & 33 & 105 & \\
\hline \multicolumn{14}{|l|}{ Lymphocyte } \\
\hline$<1.1^{*} 109$ & 13 & 26 & 3 & 0.092 & 23 & 19 & 0.031 & 34 & 8 & 0.305 & 15 & 27 & 0.401 \\
\hline $1.1-3.2$ & 64 & 133 & 32 & & 121 & 108 & & 179 & 50 & & 84 & 145 & \\
\hline$>3.2$ & 4 & 27 & 4 & & 10 & 25 & & 32 & 3 & & 9 & 26 & \\
\hline \multicolumn{14}{|l|}{ NLR } \\
\hline$<5$ & 73 & 179 & 37 & 0.135 & 144 & 145 & 0.473 & 233 & 56 & 0.316 & 101 & 188 & 0.603 \\
\hline$\geq 5$ & 8 & 7 & 2 & & 10 & 7 & & 12 & 5 & & 7 & 10 & \\
\hline \multicolumn{14}{|l|}{ Weight lost } \\
\hline No/Little & 45 & 125 & 33 & 0.001 & 103 & 100 & 0.731 & 171 & 32 & 0.006 & 66 & 137 & 0.543 \\
\hline Middle & 14 & 33 & 3 & & 21 & 29 & & 38 & 12 & & 25 & 25 & \\
\hline Large & 22 & 28 & 3 & & 30 & 23 & & 36 & 17 & & 17 & 36 & \\
\hline \multicolumn{14}{|l|}{ FBG } \\
\hline Low & 37 & 64 & 7 & 0.003 & 65 & 43 & 0.011 & 79 & 29 & 0.025 & & & \\
\hline High & 44 & 122 & 32 & & 89 & 109 & & 166 & 32 & & & & \\
\hline \multicolumn{14}{|l|}{ REE } \\
\hline Low & 71 & 82 & 1 & 0.000 & & & & 107 & 47 & 0.000 & & & \\
\hline High & 10 & 104 & 38 & & & & & 138 & 14 & & & & \\
\hline \multicolumn{14}{|l|}{ REE/kg } \\
\hline Low & 32 & 174 & 39 & 0.000 & & & & & & & & & \\
\hline High & 49 & 12 & 0 & & & & & & & & & & \\
\hline
\end{tabular}

The results were in bold, if the $95 \% \mathrm{Cl}$ excluded 1 or $p<0.05$

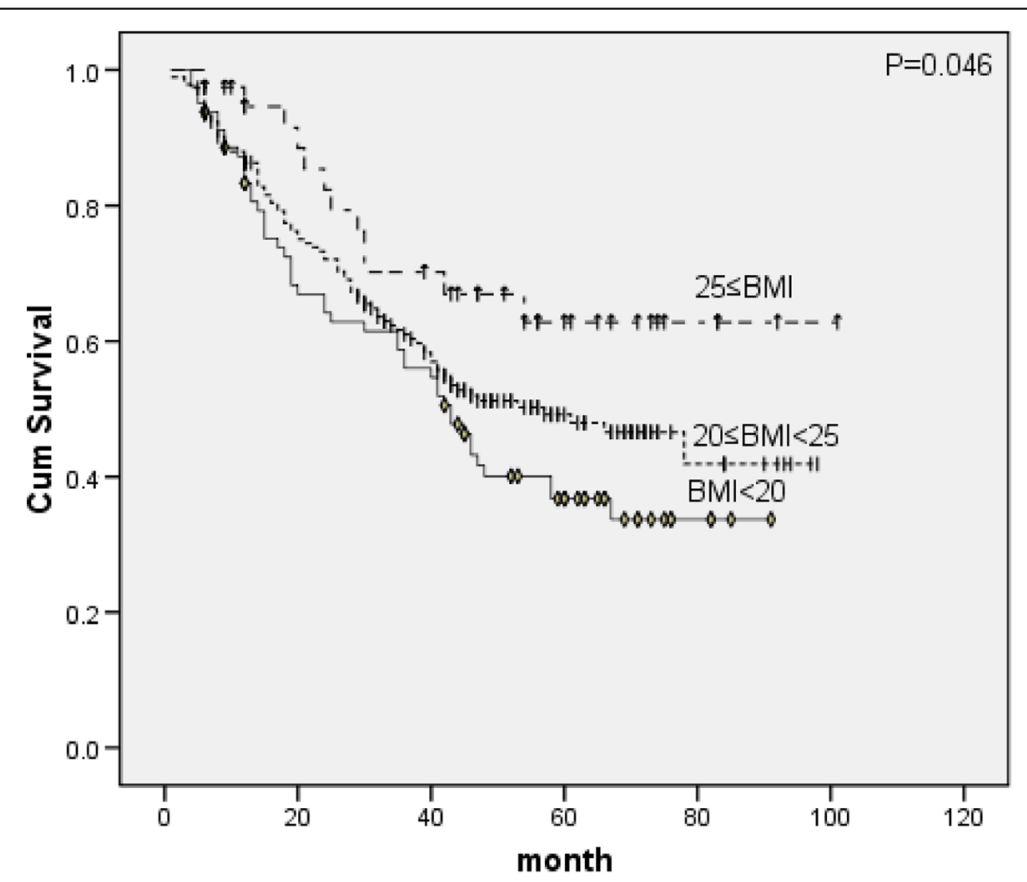

Fig. 1 Survival curves of BMI classes 


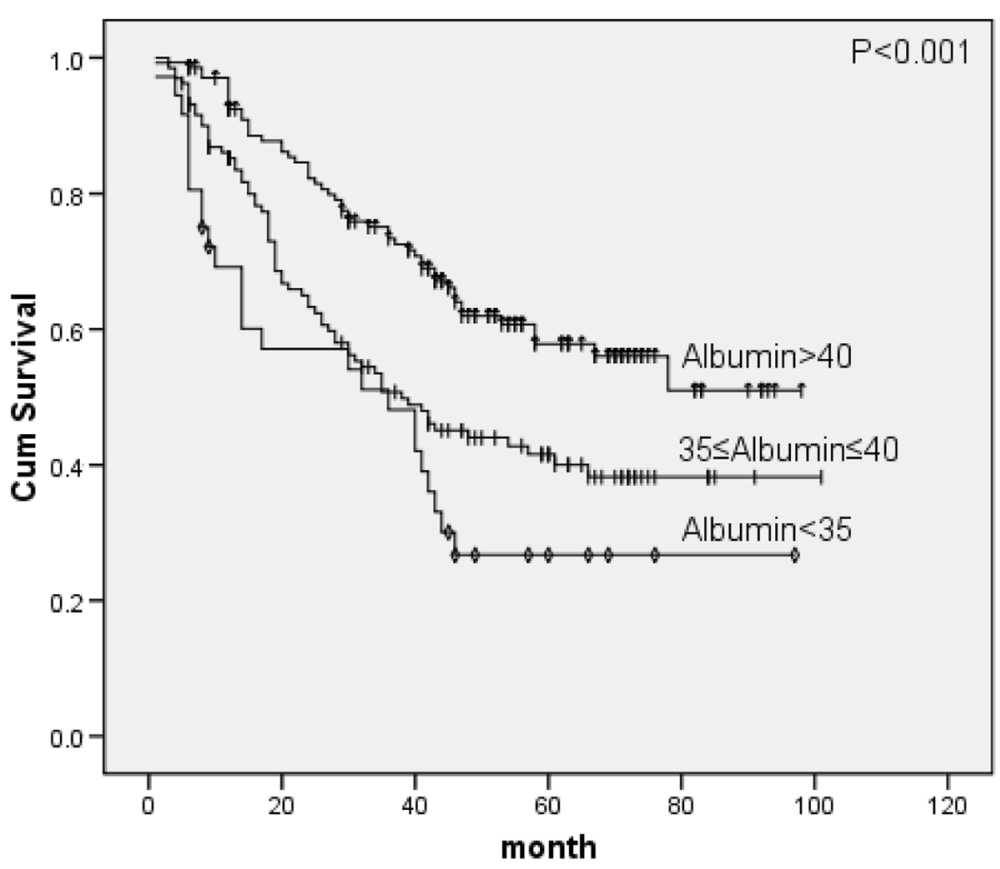

Fig. 2 Survival curves of albumin classes

whereas BMI and REE did not significantly affect the OS. However, for non-metastatic esophageal cancers, BMI and REE were important risk factors and proved to be independent prognostic indicators.

Total lymphocyte counts, NLR and serum albumin were recognized as nutrition based or inflammation- based prognostic factors. Among the cancer patients, those with digestive tract malignancies were more likely to suffer from hypoalbuminaemia, which has been attributed to increased catabolism, obstruction of the digestive tract and the systemic inflammatory response [12]. The combined use of albumin and serum $\mathrm{C}$-reactive protein

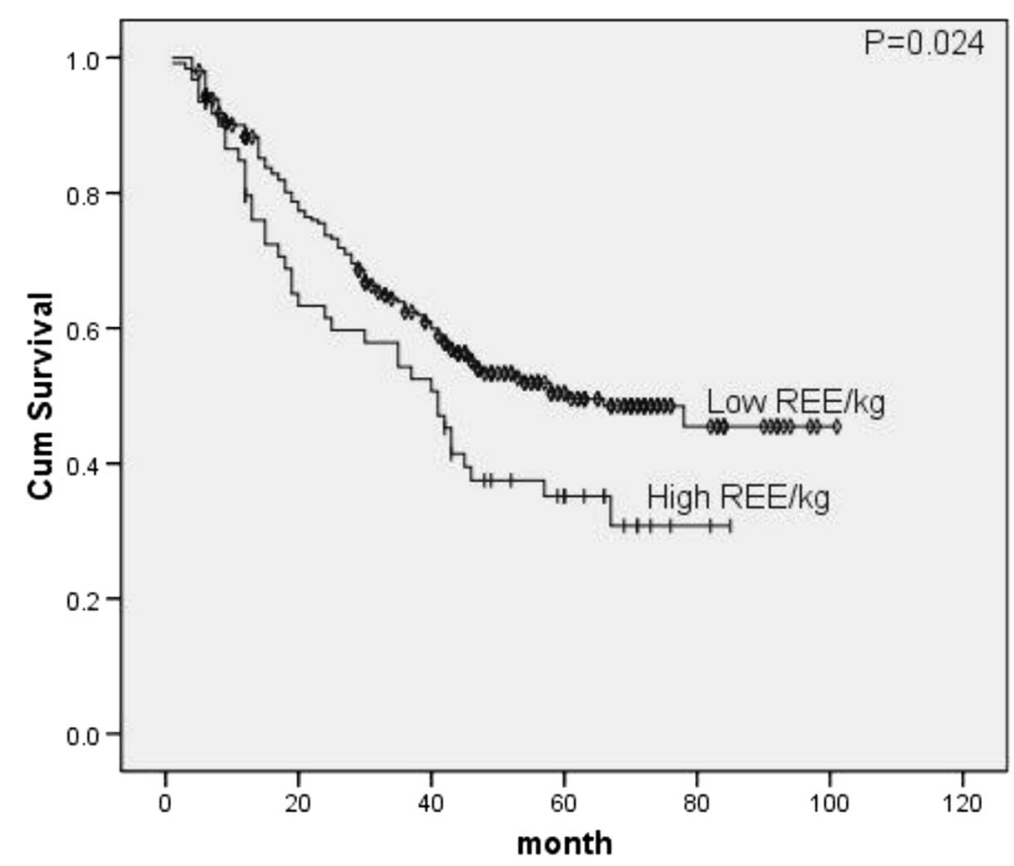

Fig. 3 Survival curves of REE/kg classes 


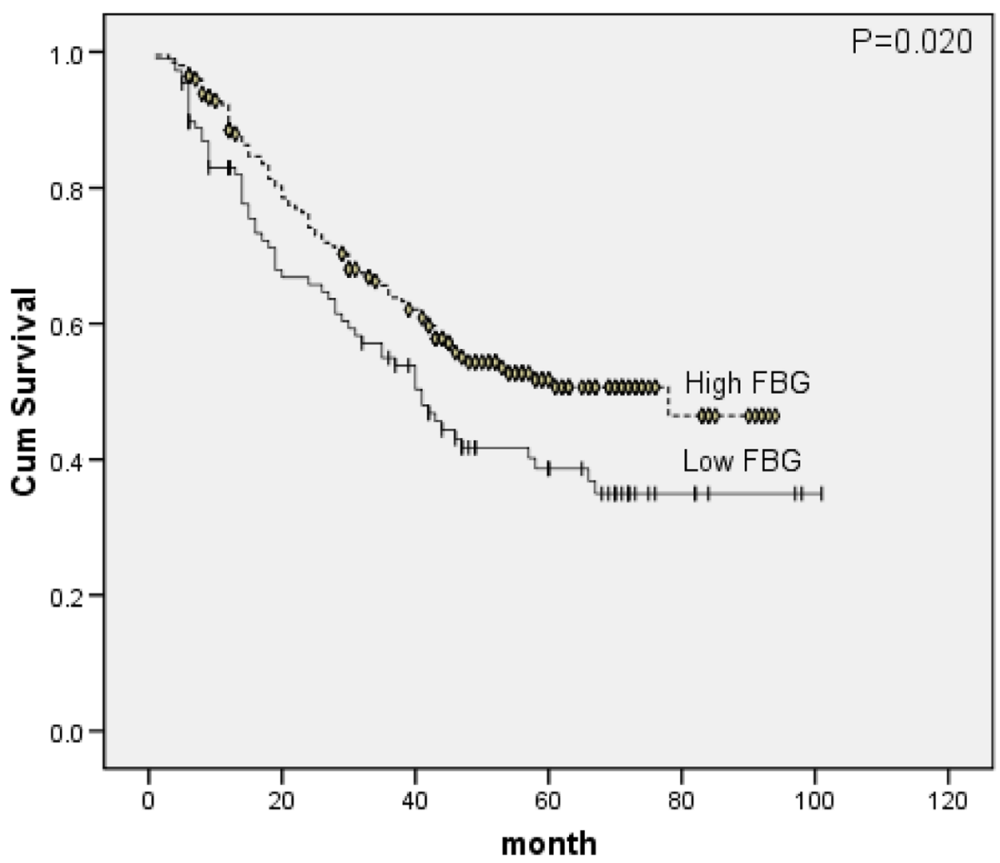

Fig. 4 Survival curves of FBG classes

were introduced by the Glasgow prognostic score [13, 14] and the combined use of albumin and lymphocyte counts have been mentioned by the Onodera's prognostic nutritional index [15]. Hypoalbuminaemia has been shown to correlate with ideal body weight, weight loss, body cell mass and poor prognostic in cancer patients [16]. In our cohort, hypoalbuminaemia associated with weight loss, low REE and low FBG. Patients with serum albumin levels $<35 \mathrm{~g} / \mathrm{l}$ had the 5 -year survival rate of $26.7 \%$, compared to $57.8 \%$ in patients with serum albu$\mathrm{min}>40 \mathrm{~g} / \mathrm{l}$. Serum albumin was proved to be an independent significant prognostic factor by multivariate analysis even after adjusting for potential confounding factors. To assess the impact of albumin on different tumor stages, we divided patients into subgroups by $\mathrm{N}$ stage (N0 vs. N1-4), and found hypoalbuminaemia as a worse survival factor in both No group $\left(X^{2}=11.078\right.$, $p=0.004)$ and N1-4 group $\left(X^{2}=7.236, p=0.027\right)$. But the multivariate prognostic analysis for subgroups of N0 and N1-4 exhibited that serum albumin as a weaker prognostic value than other potential prognostic factors. It may be explained by the different clinical characteristics of each subgroup which may impact on the prognostic value.

Table 3 Multivariate prognostic analysis

\begin{tabular}{|c|c|c|c|c|c|c|c|c|c|}
\hline \multirow[t]{2}{*}{ Factors } & \multicolumn{3}{|c|}{ All patients } & \multicolumn{3}{|c|}{ No patients } & \multicolumn{3}{|c|}{ N1-4 patients } \\
\hline & $P$ & OR & $95 \% \mathrm{Cl}$ & $\bar{P}$ & OR & $95 \% \mathrm{Cl}$ & $\bar{P}$ & OR & $95 \% \mathrm{Cl}$ \\
\hline Age & 0.001 & 1.844 & $1.279-2.661$ & 0.286 & 1.417 & $0.747-2.689$ & 0.005 & 1.982 & $1.228-3.200$ \\
\hline Sex & 0.229 & 0.757 & $0.481-1.191$ & 0.016 & 0.309 & $0.119-0.803$ & 0.465 & 0.818 & $0.478-1.401$ \\
\hline Differentiation & 0.004 & 1.560 & $1.154-2.107$ & 0.761 & 0.921 & $0.542-1.564$ & 0.002 & 1.885 & $1.267-2.805$ \\
\hline T stage & 0.005 & 1.463 & $1.125-1.903$ & 0.024 & 1.611 & $1.065-2.436$ & 0.018 & 1.528 & $1.076-2.168$ \\
\hline N stage & 0.000 & 1.610 & $1.366-1.898$ & - & - & - & 0.056 & 1.317 & $0.992-1.749$ \\
\hline $\mathrm{BMl}$ & 0.755 & 0.945 & $0.660-1.351$ & 0.035 & 0.540 & $0.304-0.959$ & 0.789 & 0.939 & $0.594-1.485$ \\
\hline REE & 0.660 & 1.101 & $0.718-1.688$ & 0.041 & 0.457 & $0.216-0.967$ & 0.163 & 1.493 & $0.851-2.619$ \\
\hline $\mathrm{REE} / \mathrm{kg}$ & 0.540 & 1.164 & $0.717-1.890$ & 0.060 & 2.054 & $0.971-4.343$ & 0.739 & 0.905 & $0.503-1.628$ \\
\hline FBG & 0.042 & 0.695 & $0.489-0.987$ & 0.632 & 0.863 & $0.474-1.574$ & 0.043 & 0.627 & $0.399-0.985$ \\
\hline Albumin & 0.030 & 0.757 & $0.589-0.973$ & 0.863 & 0.960 & $0.605-1.524$ & 0.198 & 0.819 & $0.604-1.110$ \\
\hline
\end{tabular}

$\mathrm{Cl}$ confidence interval, $O R$ odds ratio

The results were in bold, if the $95 \% \mathrm{Cl}$ excluded 1 or $p<0.05$ 
As a particular nonspecific marker of systemic inflammation, an elevated NLR is hypothesized to be associated with poor survival in various solid tumors [17]. But for esophageal cancer, its effect on long-term outcome is still controversial $[18,19]$. Most of previous studies did not find the positive predictive values of NLR in patients with esophageal cancer [20,21]. In this study, there was no significant difference in survival as the NLR cutoff value taken as five because many previous literatures reported optimal cutoff value as five [22]. We also did not find the prognostic value of total lymphocyte counts in patients with esophageal cancer.

A few studies focused on the influence of BMI on postoperative outcomes in patients with EC and had shown contradictory results, varying from no differences in postoperative complications and mortality to a higher incidence of individual complications (such as respiratory complications and anastomotic leak) in high BMI patients [5-7]. In our study, we found no difference of the frequency of postoperative complications and mortality among different BMI patients. In addition, patients with a high BMI had a higher frequency of diabetes. Smoking patients appeared to have a lower BMI. Although smoking is the preventable cause for esophageal cancer, but it was not observed to be a poor prognostic factor in our finding.

Previous studies had revealed contradictory results regarding the association between BMI and long-term outcome in esophageal cancer patients [4-7, 23-25]. Most of these studies were conducted in western populations that have a high incidence rate of EAC, which occurs more frequently in patients with a high BMI. But the main type in Chinese populations is ESCC (67.9 \% in our data). The population is prone to be lean $(26.5 \%$ with $\mathrm{BMI}<20$ and only $12.7 \%$ with $\mathrm{BMI}>25$ in our data) compared to Western populations. Based on our data, compared with normal patients, we found a significantly worse OS in low BMI patients and a significantly better OS in high BMI patients on a univariate analysis. The prognostic effect of BMI seems to be more valuable on lymph node-negative patients than lymph nodepositive patients and proved to be independent prognostic indicators.

High blood glucose level makes patients more susceptible to certain postoperative complications such as surgical site infections, sepsis, myocardial ischemia and so on [26]. But no similar studies were reported concerning esophageal cancer. Based on our date, FBG did not affect the risk of all-cause mortality and postoperative complications. Our study found low FBG level and hypoalbuminaemia are inter-related. In the class of albumin $<35 \mathrm{~g} / \mathrm{l}$, only $44.4 \%(16 / 36)$ patients had the FBG $>90 \mathrm{mg} / \mathrm{dL}$, but in the class of albumin $>40 \mathrm{~g} / \mathrm{l}$, almost $76.1 \%(105 / 138)$ patients had the FBG $>90 \mathrm{mg} / \mathrm{dL}$, and both hypoalbuminaemia and low FBG level were proved to be worse survival factors. It is easy to measure and monitor FBG or serum albumin in clinical research, so both FBG and serum albumin can easily be used for survival prognosis, and researchers can choose the appropriate method according to their laboratory conditions. To assess the impact of FBG on prognosis in patients with esophageal cancer, both the univariate and multivariate analysis proved that low FBG level $(\leq 90 \mathrm{mg} / \mathrm{dL})$ was independently associated with poor OS. These finding is consistent with previous studies which suggested that hyperglycemia related microvessel changes may have a protective effect against neoplastic cell spread and metastasis in patients with malignant tumors such as non-small cell lung cancer and so on $[27,28]$.

REE is believed to be elevated in several types of tumors, It has been hypothesized that increased energy expenditure may contribute to the development of malnutrition and weight loss [29]. Our study found patients with a low REE had significantly worse survival compared with high REE (5-year survival rate: $40.4 \%$ vs $55.3 \%, p=0.010)$. In addition, there was no significant association of REE with postoperative complications and mortality. To our knowledge, it is the first demonstration of the prognostic value of estimated REE in postoperative patients with EC. Our study also observed a significant linear correlation between BMI and REE $(p<0.001)$, showing that patients with low BMI tended to have low REE. As the estimated REE largely depends on patients' weight and height, the worse prognosis for low REE patients may reflect that these patients are under-nourished and are likely to have poor prognosis as a result. In addition, patients with low REE tended to be associated with advanced T-stages, so we concluded that the advanced tumor stages may be another reason to explain the low REE patients' worse survival.

We also explore the relationship between REE and $\mathrm{REE} / \mathrm{kg}$. We found the effect of REE on patient survival was opposite to that of REE/ $\mathrm{kg}$. Low REE as well as high REE/kg was found to be a potential worse prognostic indicator. The existing hypothesis of REE is, the sum of the metabolic activities of internal organs, muscle, bone, and adipose tissue and can reflect patient's physiques and muscle volumes, but $\mathrm{REE} / \mathrm{kg}$ may reflect the diffusion, consumption and metabolic rate of muscle. So patients with high $\mathrm{REE} / \mathrm{kg}$ have been found to lose more weight, have lower BMI and have a worse survival, this finding is consistent with the hypothesis.

In this research, low FBG was significantly associated with low BMI, albumin and REE, a potential explanation might be proposed. Individuals with esophageal cancer commonly experience metabolic abnormalities. The 
abnormal state of insulin (hyperinsulinemia or insulin resistance) is one cause, and it promotes cancer growth and progression through its effects on the insulin and insulin-like growth factor pathways [30]. Meanwhile, diabetic microangiopathy render the vascular basal membrane less digestible by tumor cells, which may play a role in impeding neoplastic cell spread and metastasis.

Following are the main limitations in our study. First, this is a retrospective study and the sample size is not large. Second, all-cause mortality is used instead of disease-specific deaths, the latter is difficult to confirm. Third, we only chose R0 patients, so our results may not be suitable for all patients.

\section{Conclusion}

In conclusion, it is the first article to explore the prognostic significance of BMI, REE and FBG among patients with EC. FBG level $\leq 90 \mathrm{mg} / \mathrm{dL}$ was independently associated with poor survival for all patients. BMI and REE were important prognostic factors and the value was significant on lymph node negative patients. Therefore it is advisable that the combined assessment of BMI, REE and FBG can be used for a better preoperative assessment and prognostic evaluation in esophageal cancer patients.

\section{Abbreviations \\ AC: Adencarcinoma; BMI: Body mass index; Cl: Confidence interval; CT: Computer tomography; DFS: Disease-free survival; EAC: Esophageal adencarcinoma; EC: Esophageal cancer; ESCC: Esophageal squamous cell carcinoma; FBG: Fasting blood glucose; HR: Hazard ratio; NLR: Neutrophil to lymphocyte ratio; OS: Overall survival; PET: Positron emission tomography; REE: Resting energy expenditure; SCC: Squamous cell carcinoma}

\section{Acknowledgements}

Not applicable.

\section{Funding}

None.

\section{Availability of data and materials}

Relevant raw data from this study can be readily available to any scientist wishing to use them for non-commercial purposes per request from the authors.

\section{Authors' contributions \\ NW, YJZ and ZMC: study design; NW, DK, LWP, GC and ZMC: data acquisition, data analysis, drafting of manuscript; All authors read and approved the final manuscript.}

\section{Competing interests}

The authors declare that they have neither financial competing interests nor non-financial (political, personal, religious, ideological, academic, intellectual, commercial or any other) competing interests. The authors declare that they have no competing interests.

\section{Consent for publication}

Not applicable.

\section{Ethics approval and consent to participate}

The study was approved by the Institutional Review Board of Huashan Hospital, Fudan University. Informed consent to participate in study was taken from the patients prior to enrolment.

\section{Author details}

${ }^{1}$ Department of Cardio-thoracic Surgery, HuaShan Hospital of Fudan University, Shanghai 200040, People's Republic of China. ${ }^{2}$ Department of General Surgery, HuaShan Hospital of Fudan University, Shanghai 200040, China.

Received: 30 May 2016 Accepted: 22 October 2016

Published online: 21 December 2016

\section{References}

1. Kamangar F, Dores GM, Anderson WF. Patterns of cancer incidence, mortality, and prevalence across five continents: defining priorities to reduce cancer disparities in different geographic regions of the world. J Clin Oncol. 2006;24:2137-50

2. Jemal A, Bray F, Center MM, Ferlay J, Ward E, Forman D. Global cancer statistics. CA Cancer J Clin. 2011;61:69-90.

3. Harvie MN, Howell A, Thatcher N, Baildam A, Campbell I. Energy balance in patients with advanced NSCLC, metastatic melanoma and metastatic breast cancer receiving chemotherapy-a longitudinal study. Br J Cancer. 2005;92:673-80.

4. Smith M, Zhou M, Whitlock G, Yang G, Offer A, Hui G, et al. Esophageal cancer and body mass index: results from a prospective study of 220,000 men in China and a meta-analysis of published studies. Int J Cancer. 2008; 122:1604-10.

5. Hayashi Y, Correa AM, Hofstetter WL, Vaporciyan AA, Rice DC, Walsh GL, et al. The influence of high body mass index on the prognosis of patients with esophageal cancer after surgery as primary therapy. Cancer. 2010;116:5619-27.

6. Yoon HH, Lewis MA, Shi Q, Khan M, Cassivi SD, Diasio RB, et al. Prognostic impact of body mass index stratified by smoking status in patients with esophageal adenocarcinoma. J Clin Oncol. 2011;29:4561-7.

7. Blom RL, Lagarde SM, Klinkenbijl JH, Busch OR, van Berge Henegouwen MI. A high body mass index in esophageal cancer patients does not influence postoperative outcome or long-term survival. Ann Surg Oncol. 2012;19:766-71.

8. Mifflin MD, St Jeor ST, Hill LA, Scott BJ, Daugherty SA, Koh YO. A new predictive equation for resting energy expenditure in healthy individuals. Am J Clin Nutr. 1990;51:241-7.

9. Rapp K, Schroeder J, Klenk J, Ulmer H, Concin H, Diem G, et al. Fasting blood glucose and cancer risk in a cohort of more than 140,000 adults in Austria. Diabetologia. 2006;49:945-52.

10. LeRoith D, Novosyadlyy R, Gallagher EJ, Lann D, Vijayakumar A, Yakar S. Obesity and type 2 diabetes are associated with an increased risk of developing cancer and a worse prognosis; epidemiological and mechanistic evidence. Exp Clin Endocrinol Diabetes. 2008;116:S4-6.

11. Nerlich AG, Hagedorn HG, Boheim M, Schleicher ED. Patients with diabetesinduced microangiopathy show a reduced frequency of carcinomas. In Vivo. 1998;12:667-70.

12. Diakos Cl, Charles KA, McMillan DC, Clarke SJ. Cancer-related inflammation and treatment effectiveness. Lancet Oncol. 2014;15:493-503.

13. Proctor MJ, Morrison DS, Talwar D, Balmer SM, O'Reilly DS, Foulis AK, et al. An inflammation-based prognostic score (mGPS) predicts cancer survival independent of tumour site: a Glasgow Inflammation Outcome Study. Br J Cancer. 2011;104:726-34.

14. McMillan DC. The systemic inflammation-based Glasgow Prognostic Score: a decade of experience in patients with cancer. Cancer Treat Rev. 2013;39:534-40.

15. Onodera T, Goseki N, Kosaki G. Prognostic nutritional index in gastrointestinal surgery of malnourished cancer patients. Nihon Geka Gakkai Zasshi. 1984;85:1001-5.

16. McMillan DC, Watson WS, O'Gorman P, Preston T, Scott HR, McArdle CS. Albumin concentrations are primarily determined by the body cell mass and the systemic inflammatory response in cancer patients with weight loss. Nutr Cancer. 2001;39:210-3.

17. Templeton AJ, McNamara MG, SŠeruga B, Vera-Badillo FE, Aneja P, Ocaña $A$, et al. Prognostic role of neutrophil-to-lymphocyte ratio in solid tumors: a systematic review and meta-analysis. J Natl Cancer Inst. 2014;106:dju124.

18. Han LH, Jia YB, Song QX, Wang JB, Wang NN, Cheng YF. The prognostic significance of preoperative lymphocyte-monocyte ratio in patients with 
resectable esophageal squamous cell carcinoma. Asian Pac J Cancer Prev. 2015;16:2245-50.

19. Xie X, Luo KJ, Hu Y, Wang JY, Chen J. Prognostic value of preoperative platelet-lymphocyte and neutrophil-lymphocyte ratio in patients undergoing surgery for esophageal squamous cell cancer. Dis Esophagus. 2014;19. doi: 10.1111/dote.12296

20. Rashid F, Waraich N, Bhatti I, Saha S, Khan RN, Ahmed J, et al. A preoperative elevated neutrophil: lymphocyte ratio does not predict survival from oesophageal cancer resection. World J Surg Oncol. 2010;8:1.

21. Dutta S, Crumley AB, Fullarton GM, Horgan PG, McMillan DC. Comparison of the prognostic value of tumour- and patient-related factors in patients undergoing potentially curative resection of oesophageal cancer. World J Surg. 2011;35:1861-6.

22. Guthrie GJ, Charles KA, Roxburgh CS, Horgan PG, McMillan DC, Clarke SJ. The systemic inflammation-based neutrophil-lymphocyte ratio: experience in patients with cancer. Crit Rev Oncol Hematol. 2013;88:218-30.

23. Grotenhuis BA, Wijnhoven BP, Hotte GJ, van der Stok EP, Tilanus HW, van Lanschot JJ. Prognostic value of body mass index on short-term and long-term outcome after resection of esophageal cancer. World I Surg. 2010;34:2621-7.

24. Melis M, Weber JM, McLoughlin JM, Siegel EM, Hoffe S, Shridhar R, et al. An elevated body mass index does not reduce survival after esophagectomy for cancer. Ann Surg Oncol. 2011;18:824-31.

25. Morgan MA, Lewis WG, Hopper AN, Escofet X, Harvard TJ, Brewster AE, et al. Prognostic significance of body mass indices for patients undergoing esophagectomy for cancer. Dis Esophagus. 2007;20:29-35.

26. Rehman HU, Mohammed K. Preoperative management of diabetic patients. Curr Surg. 2003;60:607-11.

27. De Giorgio R, Barbara G, Cecconi A, Corinaldesi R, Mancini AM. Diabetes is associated with longer survival rates in patients with malignant tumors. Arch Intern Med. 2000;160:2217.

28. Bartling B, Simm A, Sohst A, Silber RE, Hofmann HS. Effect of diabetes mellitus on the outcome of patients with resected non-small cell lung carcinoma. Gerontology. 2011;57:497-501.

29. Johnson G, Salle A, Lorimier G, Laccourreye L, Enon B, Blin V, et al. Cancer cachexia: measured and predicted resting energy expenditures for nutritional needs evaluation. Nutrition. 2008;24:443-50

30. Cannata D, Fierz Y, Vijayakumar A, LeRoith D. Type 2 diabetes and cancer: what is the connection? Mt Sinai J Med. 2010;77:197-213.

\section{Submit your next manuscript to BioMed Central and we will help you at every step:}

- We accept pre-submission inquiries

- Our selector tool helps you to find the most relevant journal

- We provide round the clock customer support

- Convenient online submission

- Thorough peer review

- Inclusion in PubMed and all major indexing services

- Maximum visibility for your research

Submit your manuscript at www.biomedcentral.com/submit
Biomed Central 